\title{
Core Loss Effects on Electrical Steel Sheet of Wound Rotor Synchronous Motor for Integrated Starter Generator
}

\author{
Choong-Sung Lee, Ji-Hyun Kim, and Jung-Pyo Hong* \\ Department of Automotive Engineering, Hanyang University, Seoul 133-791, Korea
}

(Received 15 May 2015, Received in final form 18 June 2015, Accepted 18 June 2015)

\begin{abstract}
48-V ISG (Integrated Starter Generator) system has attracted attention to improve the fuel efficiency of ICE (Internal Combustion Engine) vehicle. One of the key components that significantly affects the cost and performance of the 48-V ISG system is the motor. In an ISG motor, the core and copper loss make the motor efficiency change because the motor has a broad driving operated range and more diverse driving modes compared with other motors. When designing an ISG motor, the selection of an electrical steel sheet is important, because the electrical steel sheet directly influences the efficiency of the motor. In this paper, the efficiency of the ISG motor, considering core loss and copper loss, is analyzed by testing different types of electrical steel sheets with respect to the driving speed range and mode. Using the results of a finite element method (FEM) analysis, a method to select the electrical steel sheet is proposed. This method considers the cost of the steel sheet and the efficiency according to driving mode frequency during the design process of the motor. A wound rotor synchronous machine (WRSM) was applied to the ISG motor in this study.
\end{abstract}

Keywords : 48-V power supply system, integrated starter generator, wound rotor synchronous motor, copper loss, core loss, efficiency

\section{Introduction}

Recently strengthened fuel efficiency regulations have encouraged the mass production of electric vehicles (EVs) and hybrid electric vehicles (HEVs). However, the limitations of these vehicles include a lack of driving distance and power charging system infrastructure, and the high cost of the electric power train module that includes the motor, inverter, and battery. A realistic alternative is to improve the fuel efficiency of vehicles that use the conventional internal combustion engine, which is still in demand. One solution is the 48-V ISG (integrated starter generator) system, which allows for a simple vehicle configuration and competitive pricing compared with the EV and HEV. Development of the 48V ISG is being led by European automotive OEM and parts suppliers. The LV148, which is the standard of the $48-\mathrm{V}$ vehicle power source system, was issued by German OEMs in 2013 [1].

The reasons for adopting the $48-\mathrm{V}$ vehicle power source

(C)The Korean Magnetics Society. All rights reserved.

*Corresponding author: Tel: +82-2-2220-4466

Fax: +82-2-2220-4465, e-mail: hongjp@hanyang.ac.kr standard are as follows: (1) achievements of $\mathrm{CO}_{2}$ regulations by 2020, (2) coping with electric power shortages due to increasing high power electric systems, and (3) low development cost compared with that of EVs/HEVs by using a low voltage range in which anti-electric shock measures are unnecessary. By replacing the $12-\mathrm{V}$ alternator in vehicles that use a conventional internal combustion engine, the ISG system has a $48-\mathrm{V}$ motor/ generator that, in various driving modes, considers factors of engine efficiency such as energy regeneration, engine torque assist, and stopping/cruising on a downhill slope. The 48V ISG system seeks an improvement of $15-20 \%$ in fuel efficiency [2].

The 48-V ISG system consists of two systems, as shown in Fig. 1: a conventional $12-\mathrm{V}$ system for the vehicle, and a 48-V system for components that consume large amounts of power (e.g., the power steering system, air compressor, and lighting). The motor, which is responsible for engine-start, torque-assist, and power-generation functions, is one of the most important parts in determining the cost and performance of the 48-V ISG system. As shown in Table 1, types of motor include the claw pole [3] and the internal permanent magnet synchronous motor (IPMSM). Design methods using various motor 


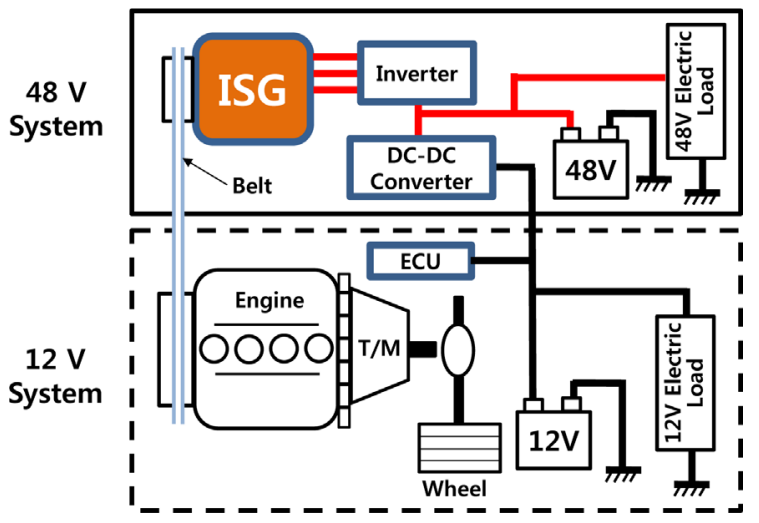

Fig. 1. (Color online) ISG system configuration [9].

Table 1. Motor types for the ISG system [10]

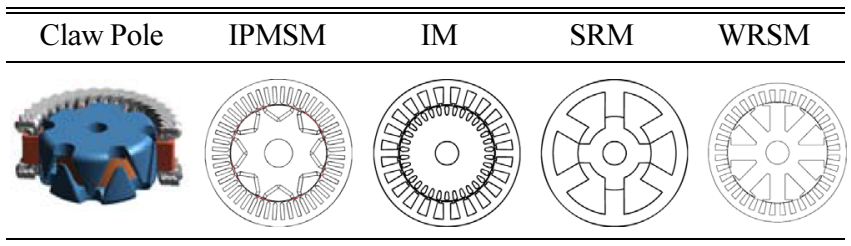

types have been proposed [3-7]. However, because the ISG motor has a broad driving speed range and various driving modes compared with other motors, the core loss and copper loss vary, which affects efficiency of ISG System.

During the initial motor design process, the selection of an electrical steel sheet directly affects the efficiency of the motor. However, research into this subject has been limited to only specific types of steel sheets. Therefore, in this paper, various electrical steel sheets are selected with different driving speeds and modes, and an efficiency analysis is performed based on the core loss and copper loss. Using the analyzed results, a method for selecting an electrical steel sheet will be proposed. This method will consider the efficiency and output according to driving mode frequency. A wound rotor synchronous machine (WRSM) was applied to the type of ISG motor in this study. This ISG motor type has many advantages in cost compared with other motors because it does not use a rare-earth magnet [8].

\section{Analysis Model}

Table 1 lists various types of ISG motor. The WRSM is a superior motor compared with the other motors because of the WRSM's efficiency and reduced size, vibration, and noise. The reasons for selecting the WRSM as a motor type of the ISG System are as follows : (1) it does not use a rare-earth magnet, and (2) it has little control burden because weak field control of high speeds is unnecessary compared with the IPMSM. In Section 2, the structure, efficiency theory, and shape of the WRSM are described. After that, an efficiency analysis is conducted by type of steel sheet under various driving speeds and modes.

\subsection{Structure of the WRSM}

The mechanical configuration of the WRSM is identical to that of the IPMSM except there are windings in the field instead of the permanent magnet, and there is a slip ring that applies current to the field windings to produce the magnetic flux in the rotor (See Fig. 2). These are fundamental differences from the IPMSM, which is the primary type of motor used in EVs and HEVs. Using the structure of the WRSM, a three-phase model can be implemented to analyze the resistance and characteristics of the motor. However, because the three-phase model is complicated, making calculations is difficult. Therefore, a model of the $d-q$ axis, which is a mathematical transformation that rotates the reference frame of the threephase model, is used. Using the $d-q$ axis model as shown

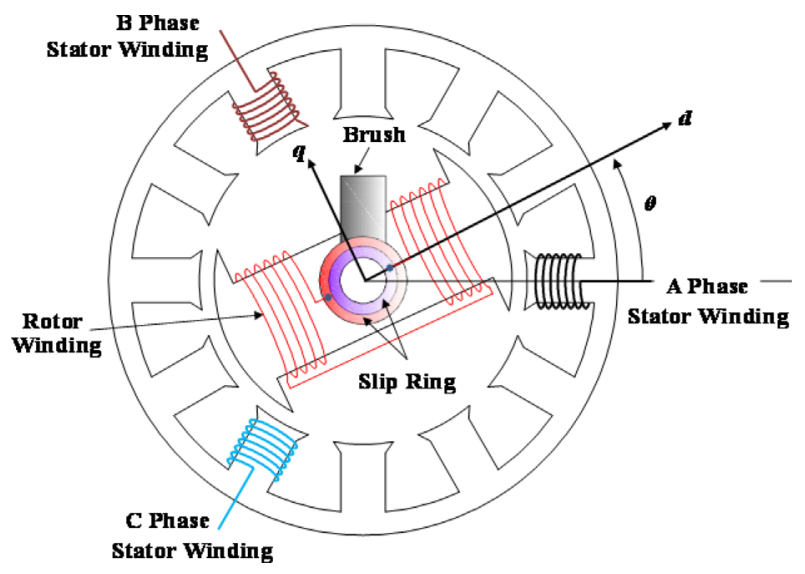

Fig. 2. (Color online) Structure of the WRSM.

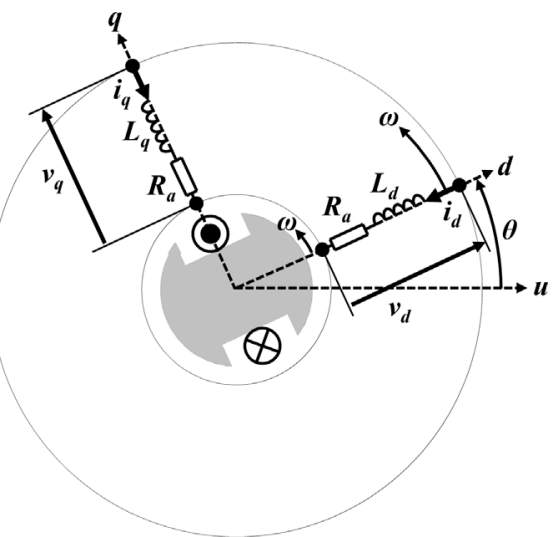

Fig. 3. $d-q$ axis model of the WRSM. 


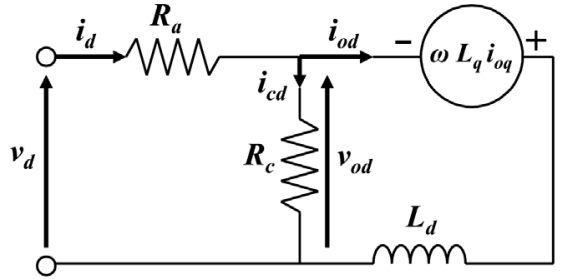

(a) $d$-axis

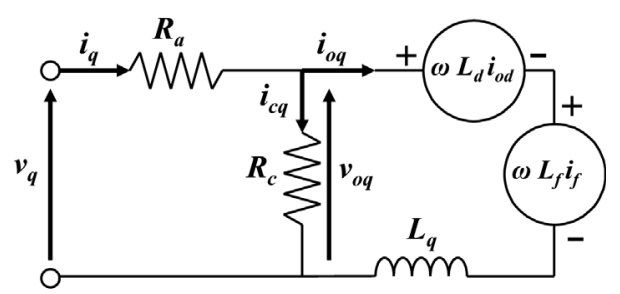

(b) $q$-axis

Fig. 4. $d$-q-axis equivalent circuit of the WRSM.

in Fig. 3, a magnetic equivalent circuit of the WRSM can be designed. The circuits of $d$ and $q$ axis are shown in Fig. 4. The torque and efficiency of the motor can be calculated by using the magnetic equivalent circuit.

\subsection{Efficiency of the WRSM}

The efficiency of the WRSM is calculated by considering the core loss and copper loss, as with a permanent magnet motor. However, the copper-loss calculation for the WRSM is different from that of a permanent magnet motor. Because there are windings in the rotor, the calculation must be performed by adding a field copper loss to the armature copper loss. The copper loss of field winding results from the resistance $R_{f}$ of the rotor winding and the current $I_{f}$ applied to the slip ring through the brush shown in Fig. 2. The copper loss of WRSM is shown in (1).

$$
P_{c}=R_{a}\left(i_{d}^{2}+i_{q}^{2}\right)+R_{f} i_{f}
$$

The core loss can be expressed by using the core loss resistance $R_{c}$ in the $d-q$ axis equivalent circuit of Fig. 4; it is proportional to the square of the magnetic flux and frequency, as shown in (2). (2) shows only the eddy current loss; and as shown in Fig. 4, this occurs because the core loss is connected in parallel with respect to the current. Although there is a method of calculating the core loss resistance through a serial model, because the result is the same as that of the parallel model method, the serial connection model was selected for this paper [11].

$$
P_{i}=\frac{V_{o}^{2}}{R_{c}}=\frac{\left(\omega_{e} \psi_{o}\right)^{2}}{R_{c}}
$$

The total loss of the WRSM consists of a core loss, copper loss, and mechanical loss. The mechanical loss can be calculated by using the mechanical design specifications for the shaft, bearing, fan, etc. However, since this is outside the scope of this study, it is ignored. Thus, the total loss $P_{\text {loss }}$ of the WRSM in this study is expressed by considering the core loss and copper loss as shown in (3).

$$
P_{\text {loss }}=P_{c}+P_{i}
$$

The efficiency can be shown by (4) and the mechanical power $P_{\text {out }}$ is a product of the rotor speed $\omega$ and torque $T$.

$$
\eta=\frac{\omega T}{\omega T+P_{\text {loss }}} \times 100=\frac{P_{\text {out }}}{P_{\text {out }}+P_{\text {loss }}} \times 100
$$

\subsection{Motor Specification}

A related case study was cited for the output power specifications and operating points of the WRSM [7]. The power specifications are the maximum power of $10 \mathrm{~kW}$ and continuous power of $4 \mathrm{~kW}$. The maximum power is the required power of the driving mode for starting torque and engine torque assist at acceleration, and continuous power is the power required by the driving mode for engine torque assist under normal driving conditions. Because the ISG motor has a broad driving speed range, considering the typical driving speed of the vehicle, the driving speed of the WRSM was limited to 2,000 rpm at engine starting and idling, 10,000 rpm at normal speed, and $15,000 \mathrm{rpm}$ at maximum speed. The required specifications for maximum power and continuous power are shown in Table 2.

To determine the geometry design of the WRSM that satisfies the specifications in Table 2, 35PN230 electrical steel sheet (typically used in the permanent magnet motors of EVs/HEVs) was applied. The major design specifications are 8-pole/36-slot with an air-gap length of $0.5 \mathrm{~mm}$. A two-dimensional cross-sectional view of the WRSM design is shown in Fig. 5. In Fig. 5, the core and coil of stator and rotor are shown by color and the electrical sheet steel is applied to the core of rotor and stator.

Table 2. Required specifications for driving speeds.

\begin{tabular}{ccccc}
\hline \hline $\begin{array}{c}\text { Maximum } \\
\text { Power } \\
(10 \mathrm{~kW})\end{array}$ & $\begin{array}{c}\text { Driving Speed } \\
{[\mathrm{rpm}]}\end{array}$ & 2,000 & 10,000 & 15,000 \\
\cline { 2 - 5 } & Torque $[\mathrm{Nm}]$ & 47.8 & 9.6 & 6.4 \\
\hline \hline $\begin{array}{c}\text { Continuous } \\
\text { Power } \\
(4 \mathrm{~kW})\end{array}$ & $\begin{array}{c}\text { Driving Speed } \\
{[\mathrm{rpm}]}\end{array}$ & 2,000 & 10,000 & 15,000 \\
\cline { 2 - 5 } & Torque $[\mathrm{Nm}]$ & 19.1 & 3.9 & 2.6 \\
\hline
\end{tabular}




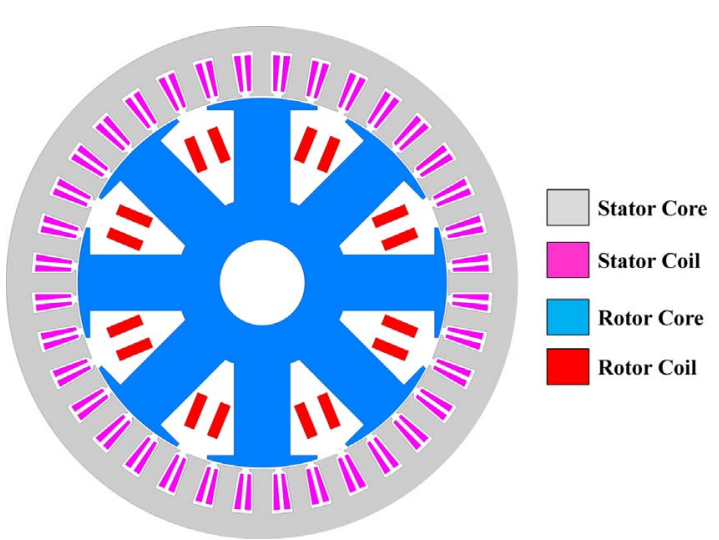

Fig. 5. (Color online) Cross-sectional view of WRSM.

\section{Efficiency Analysis}

\subsection{Analysis Conditions and Applied Steel Sheet}

Using the finite element method (FEM), the efficiency of the motor is evaluated by applying a maximum power of $10 \mathrm{~kW}$, continuous power of $4 \mathrm{~kW}$, and three types of electrical steel sheet according to rotating speed of the WRSM. The specifications listed in Table 2 are used for the analysis. The types and magnetic characteristics of electrical steel sheet are summarized in Table 3. "B50" in Table 3 indicates the magnetic flux of the material in which the magnetic field strength is induced at $5,000 \mathrm{~A} / \mathrm{m}$. "W15/50" indicates the core loss of the material measured at $50 \mathrm{~Hz}$ and $1.5 \mathrm{~T}$. "W10/400" indicates the core loss of the material measured at $400 \mathrm{~Hz}$ and $1.0 \mathrm{~T}$. Generally, in a permanent magnet synchronized motor, because the equivalent air gap is relatively large, the core-loss characteristic is more important than the magnetization characteristic of the electrical-steel-sheet. Materials with a low core loss, such as 35PN230, have been widely selected in traction motors of EV/HEV.

By contrast, with a material such as 50PN1300, because the specific resistance component for reducing the core loss of the material is lower than that of 35PN230 or 50PNE470, the core loss is larger for 50PN1300. However, because the magnetization characteristic and saturation magnetic flux density are at their highest in 50PN1300, the torque is expected to be excellent. On the other hand, for the recently developed 50PNE470 material, through texture control, the magnetization characteristic is similar to that of 50PN1300. At the same time, the core loss is relatively low.

In the case of WRSM, efficiency is important, but since the maximum torque must be limited under the required size, the rotor is designed to be oversaturated at $2 \mathrm{~T}$ or higher to maximize the power density. Thus, it is necessary
Table 3. Characteristics of electrical steel sheets.

\begin{tabular}{cccc}
\hline \hline \multirow{2}{*}{$\begin{array}{c}\text { Electrical Steel } \\
\text { Sheet Type }\end{array}$} & \multicolumn{3}{c}{$\begin{array}{c}\text { Magnetization Characteristic } \\
\text { (Representative Value) }\end{array}$} \\
\cline { 2 - 4 } & $\mathrm{B} 50[\mathrm{~T}]$ & $\mathrm{W} 15 / 50[\mathrm{~W} / \mathrm{kg}]$ & $\mathrm{W} 10 / 400[\mathrm{~W} / \mathrm{kg}]$ \\
\hline 35PN230 & 1.66 & 2.1 & 16.5 \\
50PNE470 & 1.77 & 3.1 & 33.3 \\
50PN1300 & 1.78 & 7.5 & 58.0 \\
\hline
\end{tabular}

to use an electrical steel sheet that has excellent core loss and magnetization characteristics. Therefore, the electrical steel sheet 50PNE470 was also used in this study.

\subsection{Results of Analysis}

The efficiency for the ISG motor considering the core loss and the copper loss was calculated by the equations (1)-(4).

To calculate the core loss of the ISG motor, the B-H curve of the electrical steel sheet was used as shown in Fig. 6(a). In addition, the core loss data for electrical steel sheets according to the magnetic flux density at various frequencies was also used as shown in Fig. 6(b). Fig. 7 shows the core loss calculation procedure of WRSM in this study and firstly the finite element method was performed under various the field currents $I_{f}$ and frequency $f$. Step. 1 calculates the magnetic flux density at the time domain for each element of the stator and rotor core by the finite element method. Step. 2 performs the Fourier transform to find the magnitude of the fundamental and harmonic components from the calculated magnetic flux density for each element the stator and rotor core. Step. 3 calculates the core loss corresponding to the frequency and flux density of each harmonic using the iron loss data. Step. 4 determines the total iron loss from the sum of core loss at each element of the stator and rotor core.

Applying the analysis conditions of Table 2 and electrical-steel-sheet characteristics of Table 3, the analysis results of loss and efficiency for maximum power and continuous power are shown in Table 4 and Table 5, respectively.

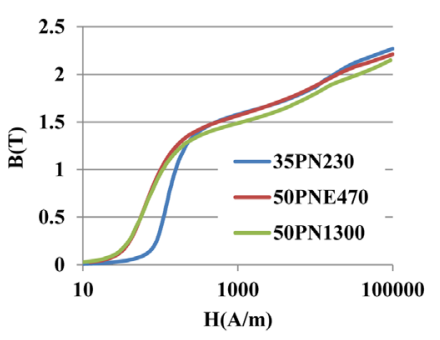

(a) B-H Curve

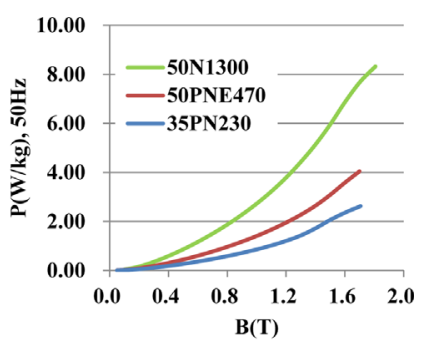

(b) Core loss data
Fig. 6. (Color online) B-H curve and core loss data. 


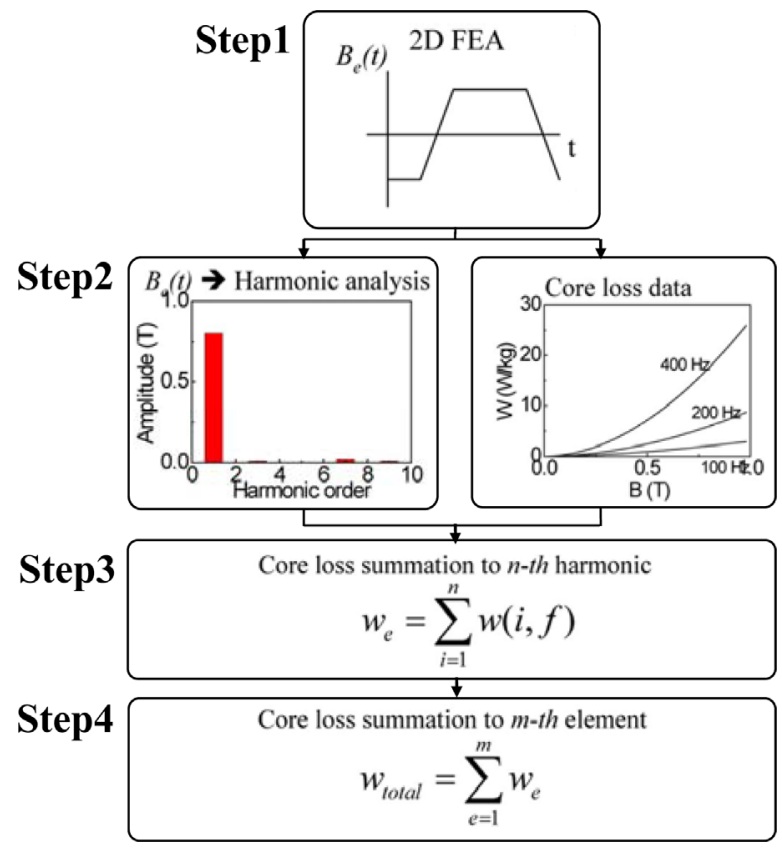

Fig. 7. (Color online) Core loss calculation procedure.

Using the analysis results from Table 4 and Table 5, comparisons between copper loss, core loss, and efficiency of different types of electrical steel sheet according to the speed of the WRSM are shown in Fig. 8-10. As can be seen in Fig. 8, in the case of $10 \mathrm{~kW}$ maximum power at a $2,000 \mathrm{rpm}$ driving speed, the core losses of 50PNE470 and 50PN1300 were a little higher than that of 35PN230. However, since the magnetization characteristic of 50PNE470 was relatively high and its saturation characteristic was excellent, a low current was needed. There- fore, copper loss was low and the efficiency was the highest among the 3 electrical steel sheets. In the case of 35PN230, because the field current and armature current were high, a saturation of the core occurred. Since the difference in magnetization characteristics was shown as the torque component, the copper loss was higher compared to that of 50PNE470 and 50PN1300.

In the case of $4 \mathrm{~kW}$ continuous power, because the required torque was low compared to that of $10 \mathrm{~kW}$ power, the copper loss was reduced and the difference in efficiency decreased compared with that of 35PN230, which showed an equivalent efficiency.

For a maximum power of $10 \mathrm{~kW}$ and continuous power of $4 \mathrm{~kW}$ at a driving speed of $10,000 \mathrm{rpm}$, the copper losses for the three types of electrical steel sheet were relatively similar compared with their core losses as shown in Fig. 9. This occurred because the saturation of the core was reduced since the field and armature currents were low, which reduced the torque component based on the differences in magnetization characteristics. At a driving speed of $15,000 \mathrm{rpm}$, similar to the driving speed of 10,000 rpm, core loss in50PNE470 and 50PN1300 increased compared with that of 30PN230based on the increase in driving speed (see Fig. 10). This led to a reduction in efficiency.

At low speeds, copper loss was dominant among the influences on motor efficiency. However, at high speeds, the effect of core loss increased, and the specific resistance component of the material increased in the following order: 35PN230, 50PNE470, and 50PN1300. Thus, at high speeds, a loss in efficiency occurred because the increase in core loss owing to eddy current was high.

Table 4. Loss and efficiency at maximum power.

\begin{tabular}{|c|c|c|c|c|c|c|c|c|c|}
\hline \multirow{2}{*}{ Analysis Item } & \multicolumn{3}{|c|}{$2,000 \mathrm{rpm}$} & \multicolumn{3}{|c|}{$10,000 \mathrm{rpm}$} & \multicolumn{3}{|c|}{$15,000 \mathrm{rpm}$} \\
\hline & $35 \mathrm{PN} 230$ & 50PNE470 & 50PN1300 & $35 \mathrm{PN} 230$ & 50PNE470 & $50 \mathrm{PN} 1300$ & $35 \mathrm{PN} 230$ & 50PNE470 & $50 \mathrm{PN} 1300$ \\
\hline Power [kW] & 10.1 & 10.1 & 10.1 & 10.1 & 10.1 & 10.1 & 10.1 & 10.1 & 10.1 \\
\hline Torque [Nm] & 48.1 & 48.1 & 48.1 & 9.6 & 9.6 & 9.6 & 6.4 & 6.4 & 6.4 \\
\hline Copper Loss [W] & 3531.4 & 3293.1 & 3266.5 & 507.1 & 448.7 & 448.0 & 1207.6 & 1194.1 & 1269.6 \\
\hline Core Loss [W] & 40.8 & 96.3 & 168.3 & 207.3 & 574.8 & 988.4 & 262.0 & 519.0 & 556.0 \\
\hline Efficiency [\%] & 73.8 & 74.8 & 74.6 & 92.9 & 90.8 & 87.5 & 87.2 & 85.4 & 84.6 \\
\hline
\end{tabular}

Table 5. Loss and efficiency at continuous power.

\begin{tabular}{|c|c|c|c|c|c|c|c|c|c|}
\hline \multirow{2}{*}{ Analysis Item } & \multicolumn{3}{|c|}{$2,000 \mathrm{rpm}$} & \multicolumn{3}{|c|}{$10,000 \mathrm{rpm}$} & \multicolumn{3}{|c|}{$15,000 \mathrm{rpm}$} \\
\hline & $35 \mathrm{PN} 230$ & 50PNE470 & 50PN1300 & $35 \mathrm{PN} 230$ & 50PNE470 & 50PN1300 & $35 \mathrm{PN} 230$ & 50PNE470 & 50PN1300 \\
\hline Power [kW] & 4.0 & 4.0 & 4.0 & 4.2 & 4.2 & 4.2 & 4.1 & 4.1 & 4.1 \\
\hline Torque [Nm] & 19.1 & 19.1 & 19.1 & 4.0 & 4.0 & 4.0 & 2.6 & 2.6 & 2.6 \\
\hline Copper Loss [W] & 719.2 & 667.5 & 669.8 & 203.5 & 202.2 & 206.7 & 251.9 & 240.3 & 214.9 \\
\hline Core Loss [W] & 42.3 & 99.0 & 181.6 & 244.5 & 561.0 & 977.0 & 275.0 & 591.0 & 734.0 \\
\hline Efficiency [\%] & 83.9 & 83.9 & 82.4 & 90.3 & 84.6 & 78.0 & 88.6 & 83.1 & 81.1 \\
\hline
\end{tabular}




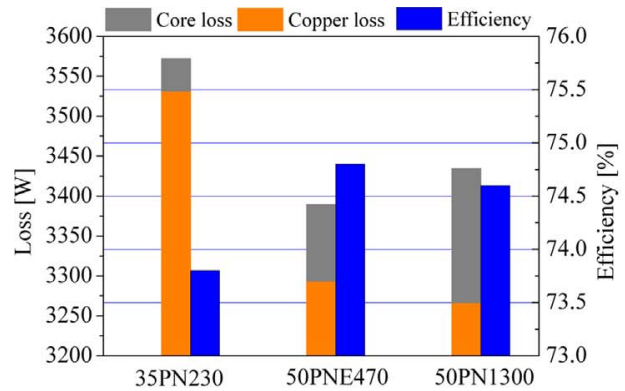

(a) Maximum power of $10 \mathrm{~kW}$

Fig. 8. (Color online) Loss and efficiency at 2,000 rpm.

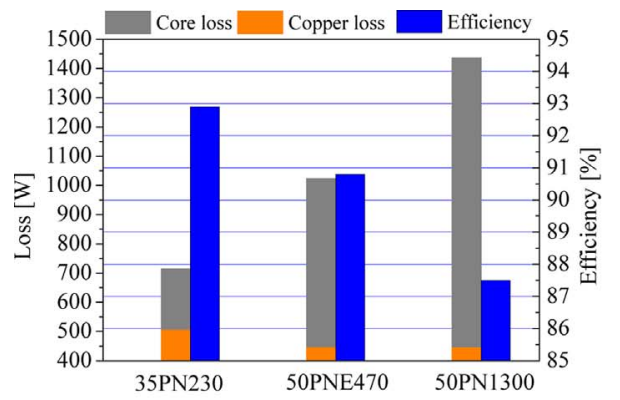

(a) Maximum power of $10 \mathrm{~kW}$

Fig. 9. (Color online) Loss and efficiency at 10,000 rpm.

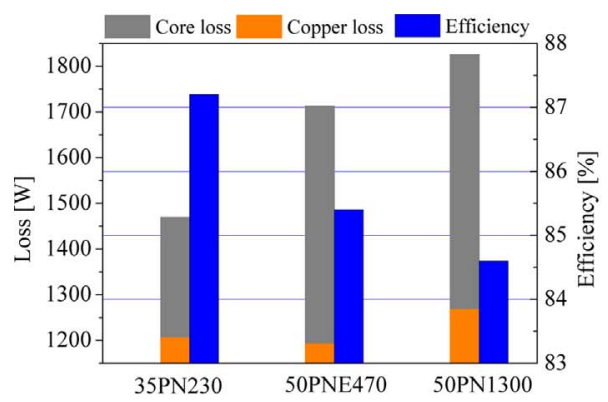

(a) Maximum power of $10 \mathrm{~kW}$

Fig. 10. (Color online) Loss and efficiency at 15,000 rpm.

Summarizing the above results: With efficiency in mind, when the use frequency of $2,000 \mathrm{rpm}$ driving mode is increased compared with that of 10,000 and 15,000 rpm, it is appropriate to select 50PNE470 as the electrical steel sheet for the motor among the three types of electrical steel sheet. By selecting this electrical steel sheet, the efficiency of the ISG motor can be maximized. The selection of 50PNE470 has more fuel efficiency in more stop \& go drive modes in urban areas than high-speed and maximum-speed drive modes in highways.

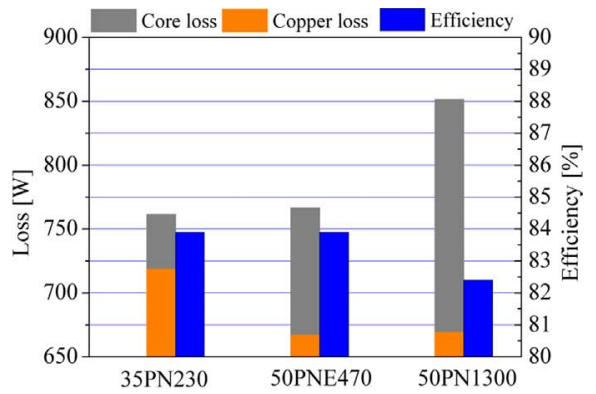

(b) Continuous power of $4 \mathrm{~kW}$

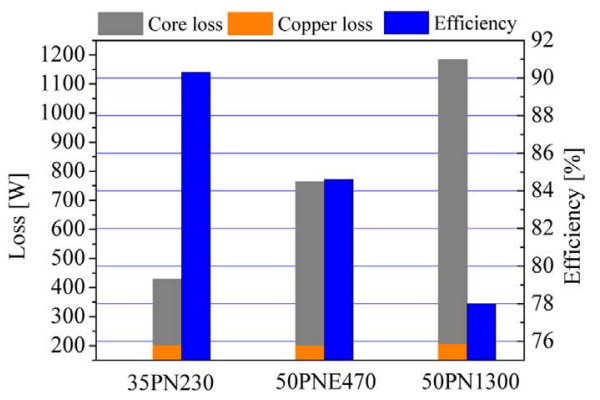

(b) Continuous power of $4 \mathrm{~kW}$

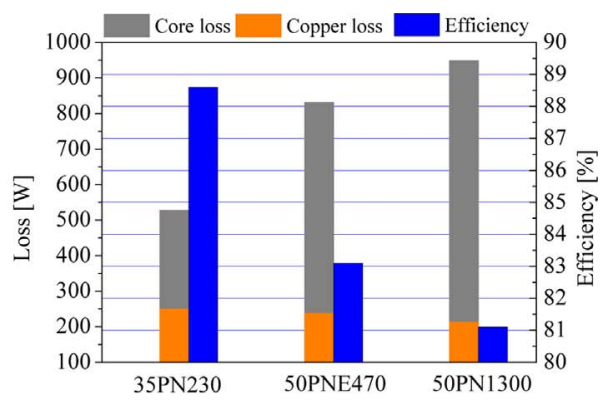

(b) Continuous power of $4 \mathrm{~kW}$

\section{Conclusion}

In this study, the efficiency of an ISG motor with a WRSM was calculated using the finite element method. The analysis considered the core loss and copper loss of the WRSM according to the type of electrical steel sheet used for the field winding of the ISG at different driving speeds. First, the specifications of maximum power and continuous power and major driving speeds were determined, and an efficiency analysis was carried out 
based on the type of electrical steel sheet. To carry out the efficiency analysis, the FEM method was applied by considering the magnetic saturation and frequency according to rotation speed with regard to inductance and core loss. The analysis results show that, to maximize efficiency when designing the motor, the electrical steel sheet should be considered after considering the use frequency of the major driving speed mode within the required driving range, and by comparing the efficiency with the effects of copper and core loss according to the motor speed.

Although this study was accomplished by limiting the WRSM type for the ISG, this can be an effective method for selecting an electrical steel sheet when designing a motor other than one with a WRSM, as shown in Table 1, by considering the cost, size, and heat dissipation on the operation of a 48-V ISG system. Furthermore, this study provides an effective method for selecting the type of electrical steel sheet when designing a motor that, like the ISG system, has abroad driving range and various driving modes.

\section{References}

[1] O. Sirch, Int. Conf. Automotive 48 V Power Supply System (2015).

[2] M. Kyupers, SAE World Congress \& Exhibition (2014).

[3] G. H. Lee, G. S. Choi, and W. C. Choi, J. Power Electronics 11, 4 (2011).

[4] A. Schmidhofer, J. Horvat, T. Gabriel, D. Prix, and M. Bichler, IEEE Con. EPE (2013).

[5] S. Jurkovic, K. M. Rahman, J. C. Morgante, and P. J. Savagian, IEEE Trans. Ind. Appl. 51, 1 (2015).

[6] J. Kelly, P. Scanes, and P. Bloore, SAE World Congress \& Exhibition (2014).

[7] S. J. Kwon, D. S. Lee, and S. Y. Jung, The Trans. KIEE 62, 9 (2013).

[8] J. P. Hong, J. Korean auto 35, 10 (2013).

[9] S. Hayashi, M. Morikawa, and M. Murakami, Denso Technical Review 8, 1 (2003).

[10] W. Cai, IEEE Con. ISA (2004).

[11] N. Urasaki, T. Senjyu, and K. Uezato, IEEE Con. PESC (2001).

[12] S. O. Kwon, J. J. Lee, B. H. Lee, J. H. Kim, K. H. Ha, and J. P. Hong, IEEE Trans. Magn. 45, 10 (2009). 